\title{
Operant control of smoking in great apes*
}

\author{
W. A. PIEPER and J. M. COLE \\ Yerkes Regional Primate Research Center \\ of Emory University and Georgia State University \\ Atlanta, Georgia 30322
}

A methodology was developed for bringing smoking behavior in great apes under the control of a contingent food reinforcer. In this procedure, Ss were required to maintain long continuous draw durations (5 sec) against lighted cigarettes in order to obtain candy rewards. By beginning with short criterional durations and gradually working up to the desired response criterion, Ss were successfully habituated to the aversive aspects of smoking. The results indicated that it is possible to both shape and maintain smoking behavior with response-contingent reinforcement. The successful implementation of this procedure suggests that the pulmonary route can be used for drug administration with nonhuman primate species.

Smoking behavior is a uniquely human phenomenon in that man is the only organism who regularly uses the pulmonary route to self-administer potentially toxic substances. While animals have been used as Ss in experiments designed to study the effects of substances contained in cigarettes, i.e., nicotine in tobacco and delta-9-tetrahydrocannabinol $\left(\Delta^{9}\right.$-THC) in marijuana, the drugs have almost always been administered orally or by injection. Since the route of administration may be an important aspect of the effectiveness of a compound, the pulmonary route should be used whenever appropriate to the drug being tested. As Jarvik (1967) has noted, although there is no apparent physiological need to inhale substances other than oxygen, absorption of compounds from the lungs by the pulmonary circulation is a route of administration which rapidly exposes the central nervous system to the drug prior to possible hepatic degradation. This increased efficiency of the pulmonary route of administration probably accounts for the popularity of smoking substances like tobacco, marijuana, and opium.

The development of a procedure whereby specified quantities of drugs can be administered to infrahuman Ss via the pulmonary route is especially desirable where ethical and experimental considerations preclude the use of human Ss. The use of this procedure with nonhuman primates is particularly advantageous because of their

This research was supported by Department of Justice Contract No. J-69-10 from the Drug Control Division, Office of Scientific Support, Bureau of Narcotics and Dangerous Drugs. Basic support of the Yerkes facility was provided by Grant RR-00165 of the Division of Research Resources, NIH. The research described in this report involved animals maintained in animal care facilities fully accredited by the American Association for Accreditation of Laboratory Animal Care. Reprints may be obtained from Walter A. Pieper, Yerkes Regional Primate Research Center, Emory University, Atlanta, Georgia 30322 . biological similarity to humans, their easily controlled environments, and the maximal manipulability of the desired treatment conditions. Several Es have reported success in teaching nonhuman primates to smoke. Jarvik (1967) reported a technique for use with rhesus monkeys, in which the Ss could obtain a water reinforcer by orally creating a momentary negative pressure on a smoking pipe containing a lighted cigarette. After initial shaping of this draw response, fixed ratio schedules were gradually introduced which required as many as 30 brief draws to obtain a single reinforcement. A similar technique was reported by Glick, Jarvik, and Nakamura (1970) and Glick, Canfield, and Jarvik (1970). In all of these experiments, however, smoking was defined in terms of a brief momentary sucking or drawing response. With this response criterion, Ss could maximize the density of reinforcement by making the required number of short-duration draws in rapid succession. Such short draws would require the displacement of only a small amount of air or smoke, and the probability of that substance reaching the lungs before expiration would appear to be relatively low. A more desirable procedure is one that would increase exposure of the smoke to the buccal tissues of the mouth and simultaneously maximize the probability of the smoke being inhaled into the lungs. Such a procedure would involve making the receipt of the primary reinforcer contingent on draws of much longer duration. By requiring that the Ss maintain drawing responses for durations of $5 \mathrm{sec}$ or more, the probability of drug absorption, either through the membranes in the mouth and pharynx or through the respiratory tissue in the lungs, would appear to be greatly increased. Manipulation of the duration of the drawing response has been successfully accomplished in this laboratory with great apes, and the general technique is believed to be suitable for use with other primate species.

\section{METHOD \\ Subjects}

One male chimpanzee (S-1), one female chimpanzee (S-2), and one male orangutan (S-3) were used as Ss. All Ss were adult animals, 12-14 years old, and were housed in the large-animal wing of the Yerkes Regional Primate Research Center.

\section{Apparatus}

All testing was done in a Lab-Care aluminum alloy test cage (Model LC-1500), which was 74 in. high $\times 42$ in. wide $\times 60$ in. long. This cage was modified by replacing one wall with a manipulandum panel constructed of $1 / 4$-in. aluminum alloy plate. $M \& M$ candy teinforcements were delivered from a Davis $M \& M$ dispenser (Model BNDP) into a recessed food receptacle, which was located in the center of this panel. A hollow metal smoking pipe, 1/4-in. diam, located $12 \mathrm{in}$. to the right of the food receptacle, extended 2 in. through the manipulandum panel into the test cage. This pipe was attached to a Carbus Model 3 
Table 1

Summary of Smoking Behavior

\begin{tabular}{|c|c|c|c|}
\hline & S 1 & S 2 & S 3 \\
\hline \multicolumn{4}{|c|}{ Rewards/Session } \\
\hline Mean & 52.20 & 49.00 & 58.20 \\
\hline SD & 2.59 & 5.43 & 8.00 \\
\hline \multicolumn{4}{|c|}{ Cumulative Negative Pressure/Session in Seconds } \\
\hline Mean & 356.5 & 331.40 & 340.80 \\
\hline SD & 21.0 & 45.80 & 55.30 \\
\hline \multicolumn{4}{|c|}{ Session Duration in Minutes } \\
\hline Mean & 18.12 & 28.10 & 36.03 \\
\hline $\mathrm{SD}$ & .94 & 10.63 & 6.32 \\
\hline \multicolumn{4}{|c|}{$\begin{array}{c}\text { Percent of Cumulative Negative Pressure Accounted } \\
\text { for by Criterional Draws }\end{array}$} \\
\hline Mean & 79.67 & 75.01 & 81.97 \\
\hline
\end{tabular}

cigarette lighting and holding machine located on the outside of the cage. This device (described by Jarvik, 1967) allowed for the automatic advancing and lighting of up to 36 cigarettes in succession. A thermistor mounted above the burning cigarette advanced the mechanism and lighted a new cigarette whenever $2 \frac{1}{2}$ in. of the previous cigarette had burned.

A pressure-sensing relay (Sensiflex fluidic switch, Model SF-1, Gagne Associates, Inc., 50 Wall St., Binghamton, New York 13901), connected to the smoking pipe, provided a signal whenever a minimal amount of negative pressure was exerted on the pipe. The smoking pipe was centered 3 in. below two $28-\mathrm{V}$ signal lamps which were 6 in. apart. These lamps were recessed in 1-in.-diam holes cut in the manipulandum panel and were shielded by $3 / 8$-in. clear Plexiglas. Both lamps were energized concurrently with the maintenance of a drawing response and provided the $S$ with a visual cue that the negative pressure was being maintained.

The test cage was located in an $8 \times 10 \mathrm{ft}$ windowless room. A white-noise generator served to mask extraneous sounds and a desk lamp provided the room with dim illumination. A tone generator, located near the food receptacle, emitted a $500-\mathrm{msec}$ tone whenever the $S$ completed a criterional draw response. This tone accompanied the delivery of the food reinforcement and served as a secondary reinforcer. A closed-circuit television camera mounted on the wall of the test room and a microphone located on the manipulandum panel allowed the $\mathbf{E}$ to monitor the Ss' behavior and the delivery of both the primary and the secondary (tone) reinforcers.

Transistorized electrical programming equipment (BRS-Foringer) was located in an adjacent control room, where printout counters and cumulative recorders were used to record response rates, reinforcement rates, time per cigarette, and the draw duration distribution. A Hunter Clockounter recorded the total cumulative seconds of negative pressure per session.

\section{Procedure}

All Ss were maintained on a 22 -h food-deprivation schedule throughout the experiment. On this schedule, Ss received their normal daily ration of food in one meal, given immediately after the daily test session. Prior to the initiation of formal training procedures, Ss were habituated to the test cage and given experience eating M\&Ms from the food receptacle.

The smoking response was defined as the maintenance of negative pressure sufficient to close the pressure-sensing relay for a fixed amount of time. Since the Ss were drawing against a cigarette, either lighted or unlighted, a constant drawing response was required in order to maintain the negative pressure. To aid the Ss in determining when sufficient negative pressure was being maintained, the two signal lamps lighted concurrently with the maintenance of sufficient pressure. When the duration criterion had been attained, the M\&M dispenser and the brief tone operated simultaneously.

During preliminary training, animals were rewarded for making successive approximations to the desired drawing response. The criterional draw duration was initially short $(200 \mathrm{msec})$, and $\mathrm{Ss}$ drew against unlighted cigarettes. As the Ss achieved these initial criterional durations, the duration was increased in successive $200-\mathrm{msec}$ increments until continuous draws of approximately $5.0 \mathrm{sec}$ were being sustained (S-1 = $5.4 \mathrm{sec}, \mathrm{S}-2=5.4 \mathrm{sec}, \mathrm{S}-3=4.8 \mathrm{sec}$ ). Subcriterional responses resulted in the interval timer being reset to zero without delivery of either the primary or secondary reinforcers.

After successfully shaping criterional draw responses in each animal on unlighted cigarettes, the cigarette lighting and advancing machine was activated. Initially, the king-size unfiltered cigarettes were perforated at the base with small holes. As the animal became adapted to the diluted smoke, the number of perforations was reduced, thereby raising the concentration of smoke. This method was continued until no air holes were needed and the $\mathrm{S}$ was drawing undiluted, full-strength cigarette smoke. This gradual habituation was used in order to shape the desired smoking response without incurring the aversive reactions to the smoke (coughing, etc.) which had previously resulted in refusal to respond.

Once stable responding had been established, the following measures were recorded for each animal on each of five successive test days: (1) number of reinforcements per session, (2) number of responses per session, (3) time per cigarette, (4) total cumulative seconds of negative pressure during each session, (5) the response distribution. Each $S$ smoked eight complete cigarettes daily. The amount of time spent on each cigarette depended on how long it took the animal to smoke $23 / 2$ in. of the total length.

To determine if drug absorption had occurred as a result of the smoking procedure, thin-layer chromatography was used to assay serial urine samples taken at 4 -h intervals starting $2 \mathrm{~h}$ after drug administration. 1 Although $\Delta^{9}$-THC was the drug of primary interest, a technique for detecting this compound in urine samples was not available and thus methamphetamine was used as the reference compound. This drug was administered on 2 successive days, once orally and once via smoking (i.e., with methamphetamine placed inside the cigarettes). Three urine samples were obtained following dosing by both the oral and the pulmonary route.

\section{RESULTS AND DISCUSSION}

Results of the present experiment indicate that operant control was gained over the smoking behavior. The response measures presented in Table 1 show that individual mean scores were approximately equivalent on rewards per session, cumulative negative pressure per session, and the percent of the total cumulative negative pressure accounted for by criterional draws. In terms of the mean number of minutes required to smoke the eight cigarettes, Ss were variable, with S-3 taking twice as long as S-1, and S-2 falling in between. For all three animals, approximately $80 \%$ of the negative pressure accumulated during each session was accounted for by criterional draws. This indicated that most draw responses met the criterional duration. Inspection of the response duration distribution (Fig. 1) further substantiated this finding. For each animal, the modal response category was the one just exceeding the criterional duration; the only other response category receiving a significant number of responses was the .0 - to $.5-\mathrm{sec}$ category. The relatively high incidence of 

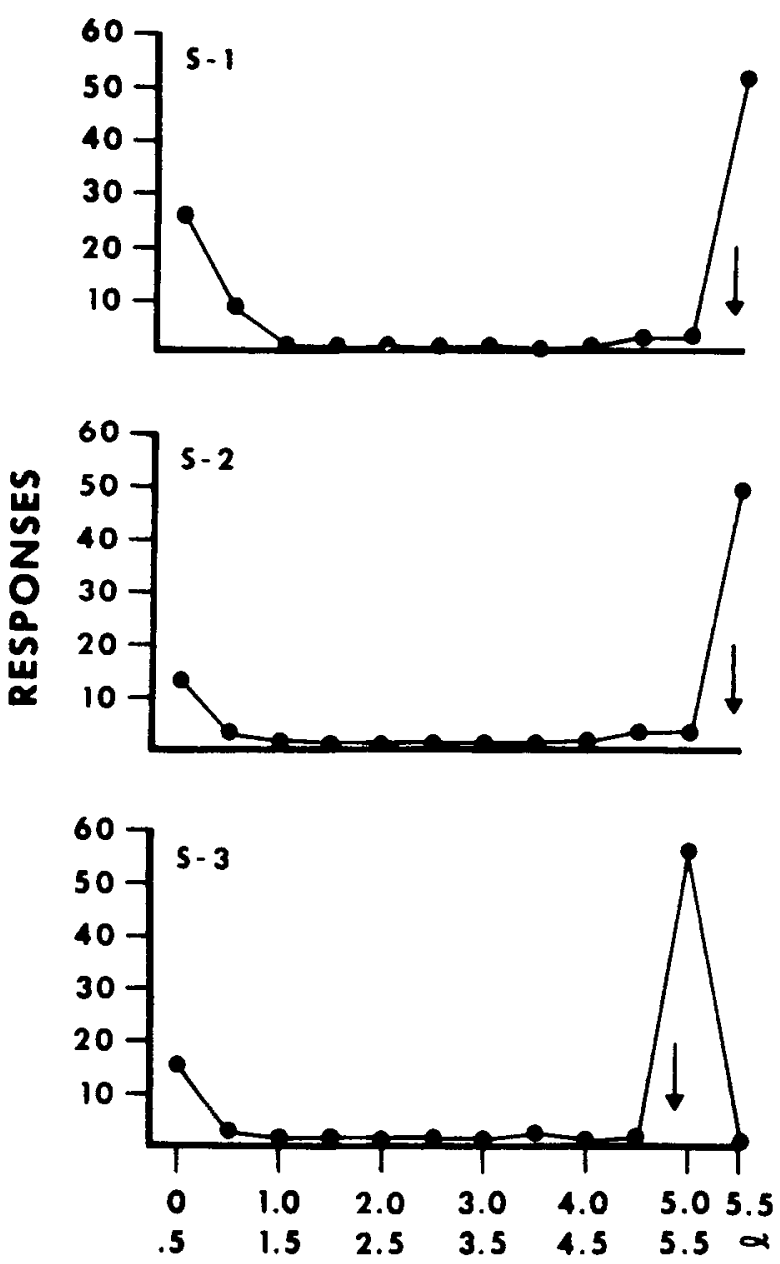

\section{RESPONSE DURATION (SEC)}

Fig. 1. Frequency distribution of smoking response durations. Arrows indicate criterional durations (S-1 and $S-2=5.4 \mathrm{sec}$; $\mathrm{S}-3=4.8 \mathrm{sec}$ ).

responses in this class resulted from the extremely brief draws that occurred when the animal appeared to be mouthing the smoking pipe prior to making a criterional draw.

The results of the chromatographic analysis demonstrated the presence of methamphetamine in the urine samples following both the oral and smoking routes of administration. Maximal amounts of methamphetamine were excreted $2 \mathrm{~h}$ following smoking and $6 \mathrm{~h}$ following oral administration. These results are consistent with the viewpoint that faster absorption occurs via the pulmonary route of drug administration. Further, behavioral evidence supporting the efficacy of this route of administration for dosing great-ape Ss with $\Delta^{9}$-THC has also been obtained (Cole, Pieper, \& Rumbaugh, 1971). In that experiment, the Ss smoked 6-10 cigarettes $30 \mathrm{~min}$ prior to testing on a DRL schedule. A consistent drug effect was observed on those days when $\Delta^{9}$-THC was added to the cigarettes. The successful implementation of the present smoking procedure indicated that quasivoluntary self-administration of vaporous compounds via the pulmonary route is possible with large nonhuman primates. This technique could likely be extended to situations utilizing smaller primate species.

\section{REFERENCES}

Cole J. M., Pieper, W. A., \& Rumbaugh, D. M. Effects of $\Delta^{\gamma}$-tetrahydrocannabinol on spaced responding in great apes. Communications in Behavioral Biology, 1971, 6(A), 285-293.

Glick, S. D., Canfield, J. L., \& Jarvik, M. E. A technique for assessing strength of a smoking preference in monkeys. Psychological Reports, 1970, 26, 707-710.

Glick, S. D., Jarvik, M. E., \& Nakamura, R. K. Inhibition by drugs of smoking behavior in monkeys. Nature, 1970, 227, 969-971.

Jarvik, M. E. Tobacco smoking in monkeys. Annals of the New York Academy of Science, 1967, 142, 280-294.

\section{NOTE}

1. We thank Dr. Trevor L. McKissick for performing the thin-layer chromatographic analyses.

(Received for publication August 20, 1972; revision received October 6,1972 .) 